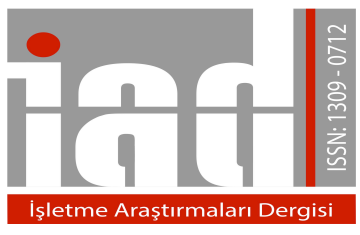

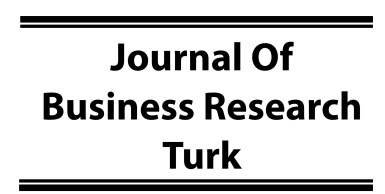

www.isarder.org

\title{
Firmaların Denetim Sonuçlarının Yönetim Kurulu Bileşenlerine Etkisi: Perakende ve Çimento Sektöründe İnceleme \\ Relationship Between Company Audit Results And Board Of Directors Components: Examination In Retail And Cement Sector
}

\author{
Tuba DERYA BASKAN \\ Kırıkkale Üniversitesi \\ İktisadi ve İdari Bilimler Fakültesi \\ İşletme Bölümü \\ Kırıkkale, Türkiye \\ orcid.org/0000-0001-8809-7043 \\ tbaskan@kku.edu.tr
}

\section{Özet}

İçinde bulunduğumuz yüzyılda yaşanan büyük muhasebe skandalları ile ortaya çıkan yeni düzenlemeler, beraberinde denetim kurumlarının faaliyetlerini hem dünya da hem de ülkemiz de kapsamlı bir şekilde yeni düzenlemelerin oluşturulması ve yasaların çıkarılmasına neden olmuştur. Bu firma içi düzenlemelerden, bağlı oldukları kurumlara ve yaptırımlara kadar değişiklik göstermektedir. Bu çalışma ile gelişmekte olan bir ekonomide perakende ve çimento sektöründe denetim raporlama sonuçlarının yönetim kurulu bileşenlerinden etkilenip etkilenmediği incelenerek firmalardaki finansal tabloların doğruluğu tespit edilmeye çalışılmıştır. Firmaların yönetim kurulu bileşenlerinden cinsiyet, büyüklük, bağımsızlık, hisse sahipliği gibi etmenler ile bağımsız denetçi görüşleri ilişkisine panel veri analizi yöntemine göre perakende ve çimento sektöründe bakılmıştır.

Anahtar Kelimeler: Denetim Raporlamaları, Yönetim Kurul Bileşenleri

\section{Absract}

In the framework of the new regulations appeared in the big accounting scandals of the last century we were inresult of our audit institution of the activities of both worlds in both countries has also been linked to a comprehensive manner to the new regulations and laws. This change varies from in-house regulations to the institutions and sanctions to which they are affiliated. This study, it was tried to determine the correctness of the financial statements in the firms by examining how the audit reports of the board components affect the retail and cement sector operating in a developing economy. The gender, age, education status, size, leadership structure and independence of the management board of the companies shall be determined and examined in relation to the opinions of the independent auditors and examined in the retail and cement sector according to the panel data analysis.

Keywords: Audit Reports, The Component of Board Directors 


\section{Kavramsal Çerçeve}

Firmaların ilişkili olduğu bilgi kullanıcılarının artması ve yeni bilgi kullanıcılarının oluşması firmaların yayınlamış olduğu finansal bilgilerin önemini artırmıştır. Firmaların yayınlamış olduğu raporlardan yöneticiler, yatırımcılar, kredi verenler, çalışanlar, devlet gibi bilgi kullanıcıları firma ile ilgili karar vermekte ona göre faaliyetlerine yön vermektedirler. Dolayısıyla bilgi kullanıcıları ile firma arasındaki bilgi ve belgelerin güvenilirliliğinin sağlanması, finansal raporların yanlış ve hatalı olmaması ya da kasıtlı yanlış hazırlanmaması bir gerekliliktir. Bu güven temelli durum ise finansal tabloların bağımsız denetim kurumları tarafından denetlenmesi ile olabilmektedir (Kaval, 2003, s. 22-23).

Kamu Gözetimi, Muhasebe ve Denetim Standartları Kuruluna bağlı olan bağımsız denetimi "Finansal tablo ve diğer finansal bilgilerin, finansal raporlama standartlarina uygunluğu ve doğruluğu hususunda, makul güvence sağlayacak yeterli ve uygun bağımsız denetim kanitlarının elde edilmesi amacıyla, denetim standartlarında öngörülen gerekli bağımsı denetim tekniklerinin uygulanarak defter, kayıt ve belgeler üzerinden denetlenmesi ve değerlendirilerek rapora bağlanması", şeklinde tanımlamıştır. Sermaye piyasası kurumu bağımsız denetimi "Bağımsız denetim, işletmelerin yillık finansal tablo ve diğer finansal bilgilerinin, bu tablo ve bilgiler için belirlenen kriterlere (örneğin, halka açık şirket finansal tablolart için Kurulca belirlenmiş veya kabul edilmiş finansal raporlama standartlarına) uygunluğu ve doğruluğu hususunda, makul güvence sağlayacak yeterli ve uygun bağımsız denetim kanıtlarının elde edilmesi amacıyla, genel kabul görmüş bağımsız denetim standartlarında öngörülen gerekli tüm bağımsız denetim tekniklerinin uygulanarak, defter, kayıt ve belgeler üzerinden denetlenmesi ve değerlendirilerek rapora bağlanması" şeklinde tanımlamıştır.

Firmalar 13/1/2011 tarihli ve 6102 sayılı Türk Ticaret Kanununun 397. maddesinin dördüncü fikrası uyarınca Bakanlar Kurulu Kararı ile belirlenen işletmeler ve yatırım fonları ile konut ve varlık finansmanı fonları yıllık finansal raporlarını bağımsız denetime tabi tutmak zorundadırlar. Bu nedenle halka açık firmalar her y1l denetimden geçmekte ve bu sonuçları resmi şekilde yayınlamak zorundadırlar. Firmaların açık, şeffaf, doğru ve güvenilir bilgileri yayınlaması bilgi kullanıcılar için önem arzetmektedir. Bu nedenle de firmaların yayınladıkları finansal tabloları için denetim kurumları tarafından yayınlanan görüşler önem arzetmektedir. Bağımsız denetim kurumlarının yayınladıkları rapor görüşleri dört şekilde oluşmaktadır (www.spk.gov.tr).

- Olumlu görüş: Finansal raporların tüm yönleri ile standartlara uygun olarak hazırlandığı, doğru ve gerçek bilgiler içerdiği yönündedir.

- Olumsuz görüş: Finansal raporların yeterli ve uygun olmadığı ve yapılan hataların finansal tablolar için önemli etkisi olduğu yönündedir.

- Görüş Bildirmekten Kaçınılan Rapor: Denetçilerin görüş bildirmek için yeterli kanıtının olmaması ve tespit edilmemiş yanlışlıkların finansal raporlar üzerindeki etkilerinin çok olacağı kanısına varılması durumunda verilen rapordur.

- Şartlı Görüş İçeren Rapor: Finansal raporlardaki yanlışlıkların tek başına veya toplu olarak önemli olduğu ya da yeterli kanıt olmamasından kaynaklı tespit 
edilemeyen yanlışlıkları olduğu ama yaygın olmaması durumunda verilen görüştür.

Çalışmanın ilerleyen kısmında firmaların denetimlerinde etkili rol oynayan yönetim kurulu bileşenleri ile ilgili literatür çalışması yapılarak, çalışmanın amacı açıklanarak, konuya ilişkin olarak perakende ve çimento sektöründe panel regresyon analizi yapılmaktadır.

\section{Literatür Taraması}

Literatür taraması neticesinde firma yönetim kurulu bileşenlerinden büyüklük, cinsiyet, yönetim kurulu büyüklüğü, Ceo, hisse sahipliği, bağımsızlık incelenmesi uygun bulunulmuştur.

Yönetim kurulu bileşenlerinden ilki cinsiyet faktörü, uzun süredir devam eden ve tartışılan bir unsurdur. Burke (1997, 2003), Zelechowski ve Bilimoria (2004) ve Stephenson (2004); yönetim kurullarında kadın istihdam eden firmaların yararlanabilecekleri rekabet avantajlarını açıklamaktadır. Yazınlarında tüketici pazarları, müşteriler, yenilikçi düşünceler ile toplumsal ve yönetimsel açıdan düşünen kadınlara sahip olan yöneticiler konsundaki noktalara değinmişlerdir. Kang vd. (2007) ile Adams ve Ferreira (2008) çalışmalarında ABD merkezli araştırmalarda kadınların komitelere katılımlarını gerçekleştirmenin değişen toplumsal tutumlarla arttığını tespit etmişlerdir. Bununla birlikte, diğer gelişmiş ülke araştırmalarında bu konuda daha az verilere rastlanmıştır. Avustralya örneğinde, Kang vd. (2007) raporunda, şirketlerin \% 33'ünde kadın müdür bulunmazken \% 51'inde sadece bir kadın bulunmaktadır. Yine Arfken vd. (2004) de 2002 deki Tennessee'deki şirketlerin sadece \% 37'sinde yönetim kurulunda en az bir kadın yönetici bulduklarını tespit etmişlerdir. Yine Adams ve Ferreira'nin (2008) çalışmalarında kadınların yönetime katılmalarının tamamen iç ve dış menfaat sahipleri karşısında meşru bir araç olarak görüldüğünü gösteren bulgular tespit edilmiştir. Bununla birlikte Catalyst (2004), 1996-2000 döneminde Amerika Birleşik Devletleri'ndeki 353 Fortune 500 şirketi rapor etmektedir. Üst yönetim ekiplerinde kadınların en fazla temsil edildiği şirketlerin özkaynaklarda \% 35 daha iyi bir getiri ve \% 34 daha iyi toplam getiri bulunmaktadır. Diğer taraftan Farrell ve Hersch (2005) kadınların daha iyi performans gösteren kurullarda hizmet verme eğiliminde olduğunu ancak yönetim kurulunda cinsiyet çeşitliliği ile performans arasında ilişki bulunamamıştır. Yine Adams ve Ferreira'nın (2008) çalışmasında hem dolaylı hem de doğrudan bağlantılar tespit etmekte, cinsiyet ve yönetim arasındaki olumlu ilişski tespit edilmiş, ancak varlıkların geri dönüşü ile cinsiyet arasında pozitif bir ilişki bulunmamaktadır.

Yönetim Kurulu bileşenlerinden ikincisi büyüklüğüdür. Lipton and Lorsch (1992) yönetim yapısı büyüdükçe müdürlerin kontrollerinin etkisinin azalıp, firmalardaki stratejik kararlar vermenin zorlaştığını ve koordine olmanın giderek güçleştiğini düşünmektedirler. Bu aşamada da yeni bir yönetim anlayışı ihtiyacı doğduğuna işaret etmişlerdir. Yine bunu tezi destekleyen Jensen (1993), yönetim kurullarında 7-8 kişiden daha fazla olduğu zaman etkili bir yönetim mücadelesinin zor olduğu ve CEO'ların kontrolünün daha kolay olduğu gözlemlenmiştir. Bununla birlikte Yermack (1996), küçük yönetim kurullarının büyük kurullardan daha etkili olduğuna dair kanıtlar sunarak, Tobin'in Q değerini piyasa değerlemesinin bir yaklaşımı olarak kullanılıp 1984-1991 yılları arasında ABD' li 452 büyük sanayi kuruluşunun bir örneğinde kurul büyüklügü ile firma değeri arasında ters bir ilişki bulmuşlardır. 
Yönetim Kurulu bileşenlerden üçüncüsü Ceo'ların varlığıdır. Donaldson (1990) "CEO ve yönetim kurulunda olan kişiler sayesinde iç veya dış belirsizlik azalmakta, firma süreçleri ve sonuçlarından sorumlu kişiler açık bir şekilde tespit edilmektedir" yöneticilik teorisine göre CEO ve yönetim kurulunda olan kişiler sayesinde iç veya diş belirsizliğin azaldığını ve firma süreçleri ve sonuçlarından sorumlu kişilerin açık bir şekilde tespit edildiğini belirtmiştir. Aynı zamanda Donaldson ve Davis (1991) CEO'ların yönetimde görevlendirilmesinin firma performansını artıracağını daha fazla hisse senedi getirisi elde edilceğini saptamışlardır. Yönetim kurulunda çalışanların aynı zamanda CEO olarak da çalışması gerektiği konusunda bir çok alternatif görüş bulunmaktadır. Donaldson (1990) yöneticilerin bakış açısı yöneticilik teorisi ile ilişkilidir. Bu teoriye göre CEO ve yönetim kurulunda olan kişiler sayesinde iç veya dış belirsizlik azalmakta, firma süreçleri ve çıktılarından sorumlu kişiler açık bir şekilde tespit edilmektedir. Ayn1 zamanda Donaldson ve Davis (1991) firma performansinı artıracağını daha fazla hisse senedi getirisi elde edileceğini saptamışlardır. Ceo'ların aynı zamanda yönetim kurulu başkanı görevlerinin ayrılmasında Liang ve Li (1999) yapmış olduğu analizinde firma kararlarını ve performansını olumlu yönde değiștiren bir sonuç bulamamışlardır. Yine CEO'lar Najjar vd (2013) tarafından hem karlılığı hem de firmaların kurumsallığını artırdığına dair bir sonuca ulaşamamışlardır.

Yönetim Kurulu bileşenlerden dördüncüsü bağımsızlık unsurudur. Firma yöneticileri arasındaki standart görüş, yönetim kurulunun bağımsızlı̆̆ının etkin olmasıdır. Fama (1980) ve Jensen (1983), yönetim kurulunun etkinliğinde yönetim kurulu üyeleri ve firma içindeki çalışanların birleşmesini önermektedir. Aynı zamanda firmanın karar sürecinde atılacak adımların belirlenmesinde dışardan katılımcıların etkili olacağını belirtmektedirler. Rosenstein ve Wyatt (1990), yönetim kuruluna dışardan katılan denetçilerin firma performansını nasıl etkilediklerini ölçmeye çalıştıkları bir çalışma yapmışlardır. Çalışmada dışardan atanan yöneticilerin maliyetinin fazla iken çok da diğer yöneticilerden daha etkin rol aldıklarına yönelik net bir bulgu tespit edememişlerdir. Diğer taraftan yönetim kurulunun bağımsızlığını artıran bu yöneticilerin firma değerini artırdığını savunmuşlardır. Brickley ve Coles yönetim kurulunun çoğunluğu dişardan ise, hisse senedi piyasasında olumlu sonuçlar oluşturduğunu tespit etmişlerdir. Bulgular dişardan yönetime katılan yöneticilerin hissedar çıkarlarını gözönüne alarak hareket edeceğini belirtilmektedir. Karpoff ve Lott'a göre firmalarda kurumsal hileler oluştuğu zaman firma dişı yöneticilerin piyasadaki itibarını zedeleyeceğinde dolayı önemli bir maliyet unsuru ile firma karşı karşıya kalır. Beasley (1996) yönetim kurulunda dışardaki üyelerin belirli oranda finansal tablolardaki hileleri etkileyip etkilemediğini incelemiş ve olumlu bir sonuç bulunmuştur. Kaufman ve Englander (2005) yönetimin bağımsızlığının sağlanması için yönetim kurulunda ilgili firma ile ticari ilişkisi bulunmayan bağımsız yönetim kurulu üyelerinin olması gerektiğini belirtmektedirler. Yazarlar yönetim kurulunun sadece hissedar çıkarını temsil etmek yerine, risk üstlenen ve stratejik bir bilgiye sahip olan paydaşlarıda temsil ettiğini öngörmektedirler. Bunun için yönetim kurulu bağımsızlığ ile firma performansı üzerinde bir çalışma yapmış ve olumlu bir sonuç tespit etmişlerdir.

Yönetim kurulu bileşenlerinden beşincisi, "blockholders (BH)" olarak geçen firma pay sahipliği ile ilgili faktördür. Literatürde denetim sonuçları ile blockholderslar arasında ilişkiyi ortaya koyan bir çalışmaya rastlanamamıştır. $\mathrm{Bu}$ nedenle burada "blockholders" kavramı üzerinde durularak yapılan çalışmalara bakılmıştır. BH= En 
Büyük Hissedarın Sermaye Tutarı/ Halka Açık Sermaye Tutarı şeklinde literatürde hesaplanan orandır. Şirkette pay sahipleri kişi ya da kurumların belirlenmesi açısından oldukça önemli bir faktördür. Aynı zamanda şirket hissedarları şirkette oy kullanma hakkına sahip olduklarından dolayı şirketin karar sürecinde önemli bir yeri bulunmaktadır. Kurumsal bir şirket yöneticisi hissedarlarını sadece fon tedarikçisi olarak görmeyip aynı zamanda firma performansının artırılmasında fikir veren olarak da görmektedir. Bu amaçla bu oran firma yönetimi için çok önemlidir (Najjar 2013). Literatürde firma performansını ve firma kurumsallığı ilişkisini araştıran çok fazla çalışmaya raslanmıştır. Ulaşılan sonuçlara göre özellikle firma yönetiminin kararlarında önemli bir rol oynamakta bunlardan belli başlıcalarını Brickley, Lase ve Smith (1988) ve Van Nuys (1993) yapmış ve BH'lerin firma yönetiminin kararlarını etkilediğine dair sonuçlara ulaşırlarken diğer taraftan Najjar (2013) yapmış olduğu çalışmanın regresyon sonuçlarına göre firma performansını artıran bir rol oynamadığını bulmuştur.

Literatür taramasından sonra çalışma perakende ve çimento sektöründe yer alan bağımsız denetçilerin görüş bildirirken yönetim kurulu bileşenlerinden etkilenip etkilenmediğinin tespit edilmesi ye çalışılmıştır.

\section{Perakende Ve Çimento Sektöründe Firmaların Denetim Sonuçlarının Yönetim Kurulu Bileşenlerine Etkisi}

\subsection{Araştırma Kapsam ve Değişkenleri}

Çalışmada 2010-2016 yıllarında KAP tarafından yayınlanan 11 perakende firmasının ve 12 çimento firmasındaki bağımsız denetim görüşü, yönetim kurulu büyüklüğü, cinsiyet dağılımı, CEO bulundurulması, bağımsızlık, en büyük hissedar yapısı ile modele firma performansı ve firma büyüklüğü kontrol değişkenleri de dahil edilmiştir.

Tablo 1. Değişken Tanımları

\begin{tabular}{|l|l|l|l|}
\hline Değişken Tanımı & $\begin{array}{l}\text { Değişken } \\
\text { Kısaltması }\end{array}$ & Tanımı & Kaynak \\
\hline Görüş & Görüş & $\begin{array}{l}\text { Olumlu,olumsuz, şartlı ve görüş } \\
\text { bildirmekteden kaçınma }\end{array}$ & KAP \\
\hline $\begin{array}{l}\text { YönetimKurulu } \\
\text { Büyüklüğü }\end{array}$ & YKbyk & Yönetim kurulu çalışan sayısı & KAP \\
\hline Cinsiyet & CNS & Kadın ve erkek olması & KAP \\
\hline Ceo Bulundurulması & CEO & $\begin{array}{l}\text { Ceo'ların yönetim kurulunda da } \\
\text { görev alıp almadığı }\end{array}$ & KAP \\
\hline Bağımsızlık & Bgsz & $\begin{array}{l}\text { Firmada dışardan denetçi olup } \\
\text { olmadığı }\end{array}$ & KAP \\
\hline Blockholders & Fbhissedar & $\begin{array}{l}\text { BH=En Büyük Hissedarın } \\
\text { Sermaye Tutarı/ Halka Açık } \\
\text { Sermaye Tutarı }\end{array}$ & KAP \\
\hline Firma Performansı & Fperf & $\begin{array}{l}\text { Vergi Sonrası Net Kâr/Aktif } \\
\text { Toplam KAP }\end{array}$ & KAP \\
\hline Firma Büyüklüğü & Fbyk & Toplam Aktif Büyüklüğü & KAP \\
\hline
\end{tabular}

Çalışmada firmaların literatürden yararlanarak yönetim kurulu bileşenleri ile denetim görüşleri ilişsisine bakılarak, denetçilerin görüşlerinde önemi tespit edilmeye 
çalışılmıştır. Bu analiz farklı iki sektörde yapılarak sektörel farklılıklar ortaya konmaya çalış1lmıştır.

\subsection{Araştırma Yöntem, Sonuç ve Yorumları}

$\mathrm{Bu}$ çalışmanın amprik yapısı panel veri seti üzerine oluşturulmuştur. Panel veri, birden çok birime ait zaman serilerinin bir arada bulunduğu veri seti ya da zaman boyutuna sahip kesit verileri olarak da tanımlanabilir. Panel veri setleri her bir kesit için eşit uzunlukta zaman serisi içeriyorsa bu tür panel verilerine "dengeli panel veri (balanced panel data)", farklı uzunluklarda zaman serisi içeriyorsa da "dengesiz panel veri (unbalanced panel data)" adı verilir (Çemrek, 2014, s.48). Buna göre çalışmanın amprik boyutunun dengeli panel analizi ile yapılması uygun görülmüştür.

$\mathrm{Bu}$ panel veri seti regresyon analizleri iki temel modelden oluşmaktadır. Bunlar sabit etkiler ve rassal etkiler modelidir. En basit sabit etkiler modeli fonksiyonu aşağıdaki gibi yazılmaktadır.

$$
\mathrm{Y}_{\mathrm{it}}=\beta_{0 \mathrm{it}}+\beta_{1 \mathrm{it}} \mathrm{X}_{1 \mathrm{it}}+\beta_{2 \mathrm{it}} \mathrm{X}_{1 \mathrm{it}} \ldots . .+\beta_{\text {kit }} \mathrm{X}_{\mathrm{kit}}+u i t
$$

Buradaki $\mathrm{Y}$ bağımlı değişkeni, i birim için $\mathrm{t}$ zamandaki gözlem değerini göstermektedir. $\mathrm{X}$ bağımsız değişkenini i birim için $\mathrm{t}$ zamandaki gözlem değerini ve $u$ bu eşitlikte bağımsız değişkenlerce gözlemlenemeyen, zamana göre değişmeyen ancak kesitlere özgü özellikleri kapsayan bireysel etki söz konusudur ve birimlere ait farklı özellikler hata terimi içerisinde yer almaktadır. Bu tür modeller tek taraflı hata bileşeni regresyon modeli adını almaktadır (Baltagi, 1995, s.11-12).

Regresyon analizlerinde bağımlı değişkeni etkileyen, ancak modelde bağımsız değişken olarak içerilmeyen değişkenlerin etkilerinin kalıntılar içerisinde yer aldığı kabul edilir. Rassal etkiler modellemesinde $\alpha_{i}$ 'nin rassal etkiler olduğu ve birimler için bağımsız ve benzer dağıldığı kabul edilir (Greene, 2003, s. 615). Rassal etkiler modeli aşağıdaki gibi yazılabilir:

$$
\mathrm{y}_{\mathrm{it}}=\beta_{0}+\beta \mathrm{x}_{\mathrm{it}}+\alpha_{\mathrm{i}}+\mathrm{u}_{\mathrm{it}}, \mathrm{u}_{\mathrm{it}} \sim B B D\left(0, \sigma_{\mathrm{u}}^{2}\right) ; \alpha_{\mathrm{i}} \sim \operatorname{IID}\left(0, \sigma_{\alpha}^{2}\right),
$$

$\mathrm{Bu}$ bilgilerden sonra çalışmamızın modeli hipotezlerimize göre oluşturulmuştur.

$\mathrm{Y}_{\mathrm{it}}=\alpha+\beta_{1}$ YKbyk $_{1 \text { it }}+\beta_{2} \mathrm{CNS}_{\mathrm{it}}+\beta_{3} \mathrm{CEO}_{1 \text { it }}+\beta_{4} \mathrm{Bgsz}_{\mathrm{it}}+\beta_{5}$ Fbhissedar $_{1 \text { it }}+\beta_{6}$ Fperf $\mathrm{CNS}_{\mathrm{it}}+\beta_{7} \mathrm{Fbyk}+u_{\mathrm{it}}$

Uygulamada sabit etkiler modeli mi rassal etkiler modelinin mi tercih edileceği Hausmann testi ile karar verilir. Bu testin fonksiyonu aşağıdaki gibi hesaplanır.

$$
\mathrm{H}=\left(\beta_{\mathrm{SE}}-\beta_{\mathrm{RE}}\right)^{\prime}\left[\operatorname{Avar}\left(\beta_{\mathrm{SE}}\right)-\operatorname{Avar}\left(\beta_{\mathrm{RE}}\right)\right]^{-1}\left(\beta_{\mathrm{SE}}-\beta_{\mathrm{RE}}\right)
$$

$\mathrm{Bu}$ eşitlikte RE alt indisi, tesadüfi etkiler modelinin tahmincilerini; SE alt indisi ise, sabit etkiler modelinin tahmincilerini göstermekte ve ayrıca Avar $\left(\beta_{\mathrm{SE}}\right)$ ve Avar $\left(\beta_{\mathrm{RE}}\right)$ ise sirasiyla, sabit ve rassal etkiler modellerinin tahmininden elde edilen asimptotik varyans kovaryans matrislerini ifade etmektedir. Hausmann testine göre prob değeri \%10'un altında ise sabit etkiler modeli, \%10'un üstünde ise rassal etkiler modelinin uygun olduğu sonucuna varılır. Çalışmamız her iki sektörde de ayrı ayrı yaplıdığında rassal etkiler modelinin kullanılması uygun olmaktadır. Buna göre perakende ve çimento sektörüne göre çıkan sonuçlar aşağıdaki tabloda gösterilmiştir. 
Tablo 2. Çimento Sektörü

\begin{tabular}{|l|l|l|l|}
\hline & $\begin{array}{l}\text { BağımlıDeğiken: } \\
\text { regression }\end{array}$ & Denetçi Görüşü- & Random Effect \\
\hline & Random effects regression & \multicolumn{2}{l|}{} \\
\hline Değişkenler & Katsay1 & İstatistik & Prob. \\
\hline CNS & 0.16 & 1.72 & 0.086 \\
\hline CEO & -0.09 & -0.43 & 0.665 \\
\hline bgsz & 0.08 & 0.36 & 0.722 \\
\hline Fbhissedar & -0.011 & -0.55 & 0.585 \\
\hline YKbyk & -0.03 & -0.68 & 0.495 \\
\hline Fperf & -0.02 & -0.11 & 0.911 \\
\hline Fbyk & 4.2 & -2.33 & 0.020 \\
\hline Hausman Testi & Prob>chi2 $=\mathbf{0 . 9 8 9 8}$ & \\
\hline
\end{tabular}

Çimento sektöründe yapılan analiz sonuçları doğrultusunda cinsiyet değişkenindeki bir birimlik artış $\% 10$ anlamlılık düzeyinde bağımsız denetçi görüşü bağımlı değişkeninde 0.16 birimlik artışa neden olmaktadır. Yine analize kontrol değişkeni olarak eklediğimiz firma büyüklüğü değişkeninde bir birimlik artış \%5 anlamlılık düzeyinde bağımsız denetçi görüşü bağımlı değişkeninde 4.2 birimlik artışa neden olmaktadır.

Tablo 3. Perakende Sektörü

\begin{tabular}{|l|l|l|l|}
\hline & $\begin{array}{l}\text { Bağıml Değiken: Denetçi Görüşü- Random Effect } \\
\text { regression }\end{array}$ \\
\hline & Random effects regression & \\
\hline Değişkenler & Katsay1 & İstatisitk & Prob. \\
\hline CNS & 0.02 & 1.16 & 1.16 \\
\hline CEO & -0.07 & -0.18 & -0.18 \\
\hline bgsz & -0.27 & -0.88 & -0.88 \\
\hline Fbhissedar & -0.03 & -0.81 & -0.81 \\
\hline YKbyk & -0.06 & -0.76 & -0.76 \\
\hline Fperf & -0.12 & -0.29 & -0.29 \\
\hline Fbyk & -2.82 & -1.20 & -1.20 \\
\hline Hausman Testi & Prob $>$ chi2 $=\mathbf{0 . 1 1 5 4}$ & \\
\hline
\end{tabular}

Perakende sektöründe yapılan analiz sonuçları doğrultusunda bağımsız denetçi görüşünü yönetim kurulu bileşenlerinden hiçbirisinin etkilemediği tespit edilmiştir. Ayrıca modele konulan firma performansı ve firma büyüklüğü kontrol değişkenlerinin hiç birisinin denetçi görüşlerini etkilemediği tespit edilmiştir.

Sonuçlara göre denetçi görüşlerinin yönetim kurulu değişkenlerinden etkilenmediği ortaya çıkmış sadece çimento sektöründe $\% 10$ anlamlılık düzeyinde cinsiyet faktörünün etkilediği belirlenmiştir. Aynı zamanda yine çimento sektöründe firma büyüklügüünün de görüşleri etkilediği ortaya çıkmıştır. Perakende sektöründe ise denetçi görüşlerinin analize konulan değişkenlerden etkilenmediği ortaya çıkmıştır. 


\section{Sonuç}

Muhasebe skandallarından sonra finansal rapor sonuçlarının denetimden geçerek yayınlanan görüşleri krediverenler, yatırımcılar, işletme sahipleri, yöneticiler, devlet gibi bir çok bilgi kullanıcı açısından önem arz etmektedir. Çalışmada literatür taraması yapılarak tespit edilen yönetim kurulu bileşenleri ile bağımsız denetim rapor görüşlerinin sonuçları arasındaki ilişki tespit edilmiştir. Bu doğrultu da İşletme yönetim kurulu bileşenlerinin bağımsız denetim kurumlarının alacakları kararlarda etkisinin olup olmadığına çimento sektörü ile perakende sektöründe ayrı ayrı analize tabi tutularak bakılması hedeflenmiştir. Böylece bu sektörlerde denetim firmalarının yayınladıkları raporlarda yönetim kurulu bileşenlerinden etkilenip etkilenmediğine ve bunun sektörler arasında farklılık oluşturup oluşturmadığını tespit edilmeye çalışılmıştır.

Çalışma da çimento sektöründe yönetim kurulu bileşenlerinden cinsiyet ile kontrol değişkeni olarak konulan firma büyüklüğü unsurlarının denetçi görüşleri üzerinde etkisi olduğu görülmektedir. Perakende sektöründe ise denetçi görüşlerinin yönetim kurulu bileşenlerinden hiçbirisi tarafından etkilenmediği tespit edilmiştir. Çalışmada bulunan sonuçlara göre denetçi görüşleri firmaların yönetim kurulunda CEO bulundurması, yönetim kurulundaki cinsiyet dağılımı, denetçilerin olması, yönetim kurulu üye sayısı, yönetim kurulundaki en büyük hissedar pay1, firma performans1, firmaların aktif büyüklüğü bileşenlerinden etkilenmemektedir. Diğer taraftan çimento sektöründe sadece cinsiyet ile firma aktif büyüklügünün denetçi görüşlerini etkilediği belirlenmiştir. Her iki sektörde de yönetim kurulu bileşenlerinden çoğunlukla etkilenmemesi deentçilerin daha şeffaf ve doğru görüşler bildirdiğini göstermektedir. Özellikle denetçilerin bağımsızlığı bileşeninden etkilenmemeleri çok önem arz etmektedir. Çünkü yönetim kurulu üyesi olan denetçi ilgili firmanın görüşlerinde etkisinin olmaması aslında olması gereken bir sonuçtur. Diğer taraftan yönetim kurulu üye sayısı ve en büyük hissedar yapısı da denetçi görüşlerini etkilememektedir. Sadece çimento sektöründe firma büyüklüğü ile cinsiyet faktörü denetçi görüşlerini etkilemektedir.

$\mathrm{Bu}$ sonuçlar doğrultusunda iki sektörde denetçi görüşleri yönetim kurulu bileşenlerinden çok fazla etkilenmemektedir. Bu da bizi görüşlerin şeffaf, tam, açık ve doğru olduğu sonucuna götürmektedir. Bunu modele kontrol değişkenleri olarak koyduğumuz firma performansı ve firma büyüklüğü tarafından da kontrol ettiğimizde sadece firma büyüklüğünün çimento sektöründe etkili olduğu tespit edilmiştir. Firma büyüdükçe denetçilerin de görüşlerinin değişmesi daha sıkı ve kapsamlı analiz yapılma ihtiyacından ileri geldiği düşünülmektedir.

Sonuçta çalışmada bulunan sonuşlara göre firmaların yönetim kurulu bileşenleri ile denetim görüşleri arasında olumsuz ilişki istenen bir sonuçtur. Türkiye de de bu konuda yapılan hem akademik hem de hukuksal çalışmaların bağımsız denetim sektörünü olumlu bir aşamaya getirdiği söylenebilmektedir. 


\section{Kaynakça}

Adams, R. B., Ferreira, D. (2008). "Women İn The Board And Theirimpact On Governance And Performance", Center for Economic Institutions Working Paper Series, No:7.

Arfken, D. E., Bellar, S. L., Helms, M. M. (2004). "The Ultimate Glass Ceiling Revisited: The Presence Of Women On Corporate Boards", Journal of Business Ethics, Vol.50, No.2, 177-186.

Baltagi B.H., (1995). Econometric Analysis Of Panel Data, John Wiley and Sons, New York.

Beasley, M., (1996). "An Empirical Analysis Of The Relation Between The Board Of Director Compositionand Financial Statement Fraud", The Accounting Review, Vol.71; No.4, 443-465.

Brickley, J. A., Lease, R. C., Smith, C. W. (1988). “Ownership Structure And Voting On Antitakeover Amendments", Journal of Financial Economics, Vol.20, 267291.

Brickley, J. A., J. L. Coles, G. Jarrell, (1997). "Leadership Structure: Separating The CEO And Chairman Of The Board", Journal of corporate Finance, Vol 3, No.3, 189-220.

Burke, R. J. (1997). "Women directors: Selection, Acceptance And Benefits Of Board Membership", Corporate Governance, Vol. 5, 118-125.

Coles, J. W., V.B McWilliams, N. Sen, (2001). "An Examination Of The Relationship Of Governance Mechanisms To Performance”, Journal of Management, Vol 27, No.1, 23-50.Çemrek, F. (2014). "Petrol Tüketiminin Ekonomik Büyüme Üzerindeki Etkisinin Panel Veri Analizi İle İncelenmesi: Avrupa Birliği Ülkeleri Ve Türkiye Örneği”, Uluslararası Alanya İşletme Fakültesi Dergisi, Cilt. 6, Say1.3, 47-58.

Donaldson, L., (1990). “The Ethereal Hand: Organization Economics And Management Theory”, Academy Of Management Review, Vol. 15, No.3, 369-381.

Donaldson, L., Davis, J.H., (1991). "Stewardship Theory Or Agency Theory: CEO Governance And Shareholder Returns", Journal Of Management, Vol. 16, No.1, 49-64.

Fama, Eugene F. (1980). "Agency Problems and the Theory of the Firm.", Journal of Political Economy, Vol. 88, No.2, 288-307.

Fama, E., Jensen, M. (1983). "Separation Of Ownership And Control”, Journal Of Law And Economics, Vol.26, No.2, 301-325.

Farrell, K. A., Hersch, P. L. (2005). "Additions To Corporate Boards: The Effect Of Gender", Journal of Corporate Finance, Vol.11, 85-106.

Greene W. H. (2003), Econometric Analysis, Fifth Edition, New York: Prentice-Hall Inc.

Jensen, M.C., (1993). “The Modern Industrial Revolution, Exit, and the Failure of Internal Control Systems", The Journal of Finance, Vol. 48, No.3, 831-880. 
Kang, H., Cheng, M., Gray, S. J. (2007). "Corporate governance and board composition: Diversity and independence of Australian Boards", Corporate Governance: An International Review, Vol.15, No.2, 194-207.

Karpoff, J. M., Lott, J.R., (1993) , The Reputational Penalty Firms Bear from Committing Criminal Fraud, Vol 32, No.2, 757- 767.Kaufman, A. , Englander E., (2005), Team Production Model of Corporate Governance, The Academy of Management Executive, Vol. 19, No.3, 9-22.

Kaval, H. 2003. Muhasebe Denetimi, Akademik Denetim Danışmanlık YMM, Ankara.

Liang, N., Li J.(1999). “ Board Structure and Firm Performance: New Evidence from China's Private Firms", Academy of Management Annual Conference, 7-10 August, Chicago, USA.

Lipton, M. , J. Lorch, (1992). “A Modest Proposal For İmproved Corporate Governance", The Business Lawyer, Vol. 48, 59-77.

Najjar,N.,(2013). “The Impact of Corporate Governance on the Insurance Firm's Performance in Bahrain", International Journal of Learning Development, Vol. 3, No.2, 56- 69.

Özcan, S., C. Elitaş. (2015), "Finansman Aracı Olarak Sukuk ve Muhasebeleştirilmesi”, Muhasebe Bilim Dünyası Dergisi, Cilt.17, Say1.3, 559-586.

Stephenson, C. (2004). "Leveraging Diversity To Maximum Advantage: The Business Case For Appointing More Women To Boards", IveyBusiness Journal, Vol.69, No.1, 1-5.

Yermack, D., (1996). "Higher Market Valuation Of Companies With A Small Board Of Directors", Journal of Financial Economics, Vol 40, 185- 211.

Van Nuys, K. (1993). "Corporate Governance Through The Proxy Process: Evidence From The 1989 Honeywell Proxy Solicitation", Journal of Financial Economics, Vol. 34, 101-132.

Zelechowski, D. D., Bilimoria, D. (2004). "Characteristics of women and men corporate inside directors in the US", Corporate Governance: An International Review, Vol.12, No.3, 337-342.

Kamu Gözetim Kurumu (KGK), (erişim tarihi: 27.07.2017).

http://www.kgk.gov.tr/DynamicContentDetail/5136/yönetmelik,

Sermaye Piyasası Kurumu (SPK), (erişim tarihi: 27.07.2017), http://www.spk.gov.tr/indexcont.aspx?action=showpage\&menuid $=6 \& p i d=9 \&$ subi $\mathrm{d}=1$, 


\title{
Relationship Between Company Audit Results And Board Of Directors Components: Examination In Retail And Cement Sector
}

\author{
Tuba DERYA BASKAN \\ Kırıkkale University \\ Faculty of Economics and Administrative Science \\ Department of Business Management \\ Kirıkkale, Turkey \\ orcid.org/0000-0001-8809-7043 \\ tbaskan@kku.edu.tr
}

\section{Introduction}

In the framework of the new regulations appeared in the big accounting scandals of the last century we were inresult of our audit institution of the activities of both worlds in both countries has also been linked to a comprehensive manner to the new regulations and laws. This change varies from in-house regulations to the institutions and sanctions to which they are affiliated. This study, it was tried to determine the correctness of the financial statements in the firms by examining how the audit reports of the board components affect the retail and cement sector operating in a developing economy. The gender, age, education status, size, leadership structure and independence of the management board of the companies shall be determined and examined in relation to the opinions of the independent auditors and examined in the retail and cement sector according to the panel data analysis.

\section{Examination of Board Members}

As a result of the literature review, it was decided to examine the gender, age, independence, leadership structure and size of the company board members.

Gender of Board Members; The gender factor of the board components is a continuing and controversial element. Burke (1997, 2003), Zelechowski and Scienceoria (2004) and Stephenson (2004); explains the competitive advantages that companies employing women in the board of directors can benefit. In the articles, the managers who have consumer markets, customers, innovative thoughts, and women who think socially and administratively have touched on the point of conscience. Kang et al. (2007) and Adams and Ferreira (2008) found that in US-based research, women's participation in committees increased with changing social attitudes. However, less research has been done in other developed country surveys. Catalyst (2004) reports 353 Fortune 500 companies in the United States during 1996-2000. Companies with the highest representation of women in senior management teams have a $35 \%$ better return and 34\% better overall return in equity. On the other hand, Farrell and Hersch (2005) found that women tend to serve in better performing institutions, but there was no relationship between gender diversity and performance on the governing board. Again in the study of Adams and Ferreira (2008), both indirect and direct connections were found, positive relationship between gender and management was determined, but there is a positive relationship between return of assets and gender

Age Status of Board Members; The management of the firm is mainly composed of a mature and experienced management board (Kang et al. 2007, p.197). In 
Gilpatrick's (2000) study, managers who are mature and older than the less experienced and younger age groups, appear to be higher on board memberships. Murray (1989) argues that individuals with similar values of a homogeneous governing body and having the same historical events should be formed. Since such management boards will be more familiar with the company and its values, it has been determined that healthier targets will be set and communication will be done more accurately. Houle (1990) argues, however, that an age-agnostic steering committee can provide a more efficient division of labor; mature, experienced and financially resourceful middle age group, while young group managers are open to innovation and provide the dynamics of business knowledge. However, Murray (1989) argues that decisions that support shortand long-term growth can lead to incompatibilities stemming from these age groups in the executive board.

Board of Directors and Leadership Structure; Kesner and Johnson, (1990); Lorsch and MacIver, (1989); Rechner and Dalton, (1990), there are many alternative views on the need for the board of directors to work as CEO at the same time. According to Dobrzynski (1995), some managers consider separating these roles only as emergency precautions and that some companies in financial difficulties require a temporary restructuring process. Anderson and Anthony (1986); Donaldson (1990); Finkelstein and Lorsch (1993) view of managers is related to managerial theory. According to this theory, internal and external uncertainty is reduced by the persons who are in the CEO and the board of directors, and the persons responsible for the company processes and outputs are clearly identified. At the same time, Donaldson and Davis (1991) found that increasing stock performance would result in more stock returns.

Board of Directors and Independence; The standard view among company managers is that the independence of the board is effective. Fama (1980) and Fama and Jensen (1983) propose the union of board members and employees within the firm at the effectiveness of the board of directors. Rosenstein and Wyatt (1990) found that adding another external director to the board increased corporate value. Brickley, Coles, and Terry (1994) found that the majority of board members had positive outcomes on the stock market. It is stated that the executives who take part in the management from outside the bullfight will act by considering the interests of the shareholder. According to Karpoff and Lott, firms are faced with a significant cost factor because of the fact that when corporate fraud occurs in firms, they will damage the reputation of non-company managers in the market. Beasley (1996) examined whether a large proportion of the members of the board of directors on the board had affected the deeds in the financial statements in particular and found a positive result.

Board Size; Lipton and Lorsch (1992) thinks that as management grows, the effectiveness of managers' controls is diminishing, and it becomes increasingly difficult to coordinate the difficulties of making firm strategic decisions. At this stage, they pointed out that a new understanding of management was needed. Again, Jensen (1993), who supported this argument, observed that an effective management struggle is difficult and the CEO is easier to control when there are more than seven to eight executive board members. Holthausen and Larcker (1993) found a positive relationship between board size and CEO's value, but found no consistent finding that there was a relationship between board size and company performance. 
Control of Audit Institutions; The reports of the audit institutions include partners, investors, investors, managers, business people, buyers, trade unions, professional chambers, government, social security institutions, and closely monitored by following the developments in this information and the information contained in the financial statements of the enterprises. Auditing firms have a very important role in institutionalization, correct operation and reliable results in reducing accounting errors and frauds, which is achieved by both the internal and external audit of management and board members.

\section{Data and Analysis}

The study included variables such as independent audit opinion, board size, gender distribution, CEO ownership, independence, largest shareholder structure, model company performance and firm size control variables for 11 retail companies and 12 cement companies published by KAP in 2010-2016.

In the study, companies were tried to determine the importance of the opinions of the auditors by looking at the relation between the board members and audit opinions by using the literature. This analysis was carried out in two different sectors and tried to reveal sectoral differences. It was deemed appropriate to conduct the empirical dimension of the study with a balanced panel analysis. After this information, the model of our work is based on our hypotheses.

$\mathrm{Y}_{\mathrm{it}}=\alpha+\beta_{1}$ YKbyk $_{1 \text { it }}+\beta_{2} \mathrm{CNS}_{\mathrm{it}}+\beta_{3} \mathrm{CEO}_{1 \mathrm{it}}+\beta_{4}$ Bgsz $_{\text {it }}+\beta_{5}$ Fbhissedar $_{1 \text { it }}+\beta_{6}$ Fperf $\mathrm{CNS}_{\mathrm{it}}+\beta_{7} \mathrm{Fbyk}+u_{\mathrm{it}}$

\section{Result}

The study also shows that the factors of firm size, which are defined as gender and control variables in the cement sector, are influential on auditor opinions. In the retail sector, it has been determined that auditor opinions are not influenced by any of the board members. In other words, according to the results found in the summer, auditor opinions are not affected by the presence of CEOs in the board of directors, gender distribution in the board of directors, auditors, number of board members, largest shareholder share in the board, company performance, On the other hand, it has been determined that only the gender and firm size of assets in the cement sector affect auditor opinions. The fact that they are mostly not influenced by the components of the board in both sectors shows that the delegates report more transparent and correct opinions. In particular, it is very important that auditors are not affected by the independence component. Because the auditor, who is a member of the board of directors, has no effect in the opinion of the relevant company, in fact it should be a result. On the other hand, the number of board members and the largest shareholder structure do not affect the opinions of the auditors. Only in the cement sector the size of the firm and the gender factor affect the auditor's views. In line with these results, the opinions of the auditors in the two sectors are not affected much by the components of the board. This leads us to the fact that the views are transparent, complete, clear and accurate. When we check this by model performance variables and company size, we found that only firm size is effective in cement sector. As the firm grows, changes in the views of auditors are thought to have led to a need for more rigorous and comprehensive analysis. 
In this study, a literature review with the board of directors will be studied to determine the relationship between variables revealed the results of an independent audit report opinion. In other words, the board of directors in accordance with the present situation with the position of employees with accounting scandals will be studied to determine the relationship between the audit report with significant results. Retail sector and cement sector in mind, this framework will be subject to a separate analysis, so that will be identified in the differences between sectors and by determining the relationship with the board components of the audit firm it aims to contribute to the literature. 